\title{
Calcified thymoma: An egg in the chest
}

\author{
Lei Yu, MD, Enyi Shi, MD, PhD, and Tianxiang Gu, MD, PhD
}

\begin{abstract}
A 46-year-old man was admitted to The First Affiliated Hospital with a 3-month history of progressive dyspnea on exertion and a weight loss of approximately $5 \mathrm{~kg}$. There were no symptoms of myasthenia gravis, such as weakness, ptosis, or diplopia. His laboratory test results showed no significant abnormality. The posteroanterior chest x-ray revealed a huge circular dense mass in the left mediastinum (Figure 1, A). Chest computed tomography demonstrated an elliptic mass with a well-defined calcified outer shell in the left anterior mediastinum (Figure 1, B, C). Three-dimensional reconstruction of thoracic computed tomography scan revealed a globular mass within the anterior mediastina with a visible nourishing blood vessel, without apparent invasive growth into the adjacent structures (Figure 1,D).
\end{abstract}

At operation, a midline incision of the chest was performed, and a firm, large calcified mass was discovered in the left anterior mediastinum without extension into the thoracic cavity and the pericardium (Figure 2, A). The wellencapsulated tumor was removed with all mediastinal adipose tissue. The tumor was elliptic in shape and measured $5 \times 4 \mathrm{~cm}$; on cut, the mass appeared as a calcified outer shell just like an eggshell (Figure 2, B), inside which there was a great deal of yellowish liquid and some solid tissue with a macroscopic appearance like fish meat (Figure 2, C). On the basis of the World Health Organization classification, the solid tissue was diagnosed as a type B1 thymoma (Figure 2,D).

From the Department of Cardiac Surgery, The First Affiliated Hospital of China Medical University, Shenyang, P.R. China.

Disclosures: Authors have nothing to disclose with regard to commercial support.

Received for publication Sept 2, 2010; accepted for publication Sept 22, 2010; available ahead of print Nov 19, 2010.

Address for reprints: Tianxiang Gu, MD, PhD, Department of Cardiac Surgery, The First Affiliated Hospital, China Medical University, Shenyang, P.R. China, 110001 (E-mail: shienyi2002@hotmail.com).

J Thorac Cardiovasc Surg 2011;142:216-8

$0022-5223 / \$ 36.00$

Copyright (C) 2011 by The American Association for Thoracic Surgery

doi:10.1016/j.jtcvs.2010.09.026 

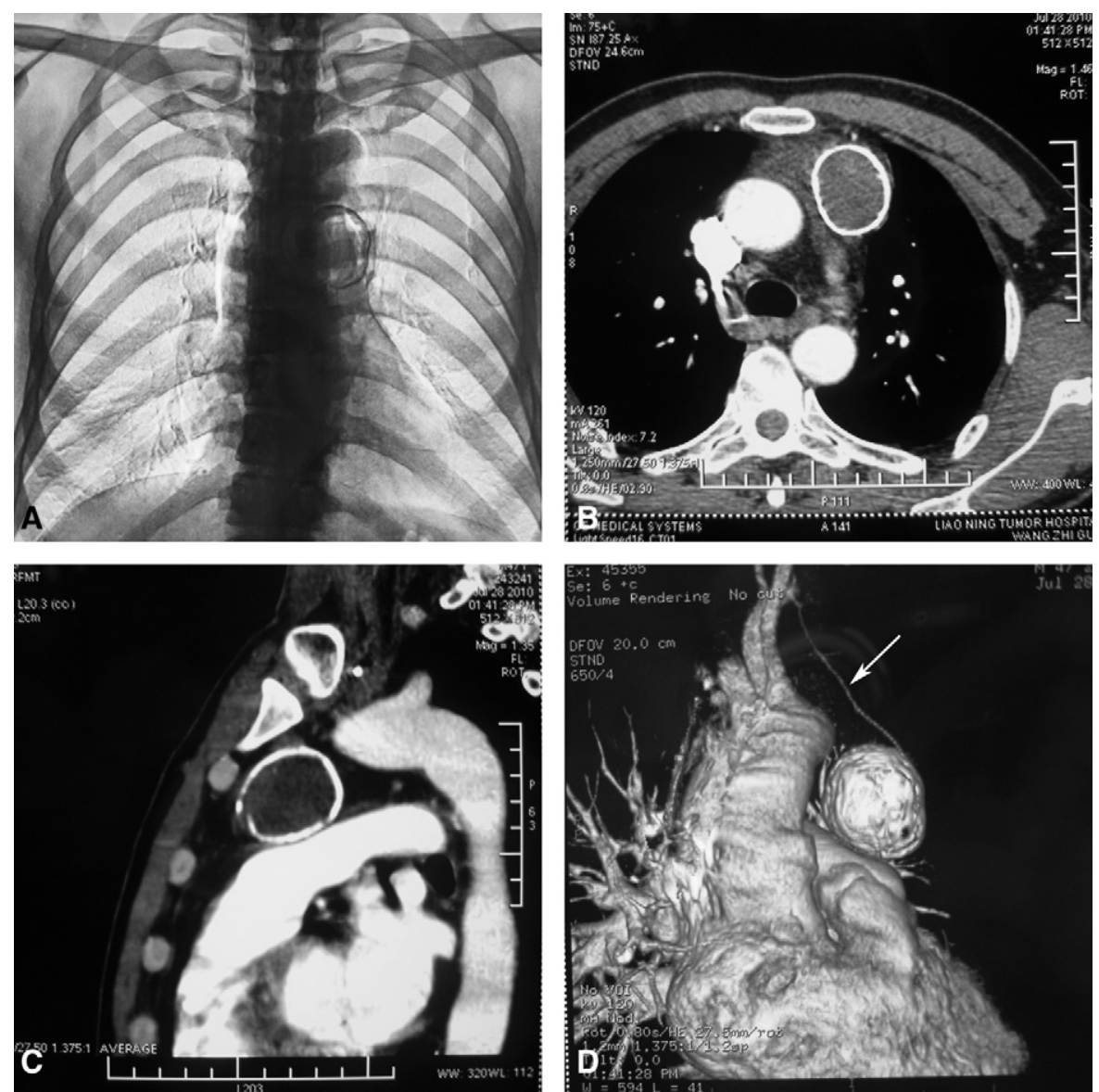

FIGURE 1. A, Huge circular dense mass in the left mediastinum is shown on posteroanterior chest radiographs. B, C, Axial and sagittal computed tomography scan shows an elliptic mass with a well-defined calcified outer shell in the left anterior mediastinum. D, Three-dimensional reconstruction of thoracic computed tomography scan demonstrates an anterior mediastinal globular mass in close apposition to the left pulmonary artery with a visible nourishing blood vessel (arrow). 

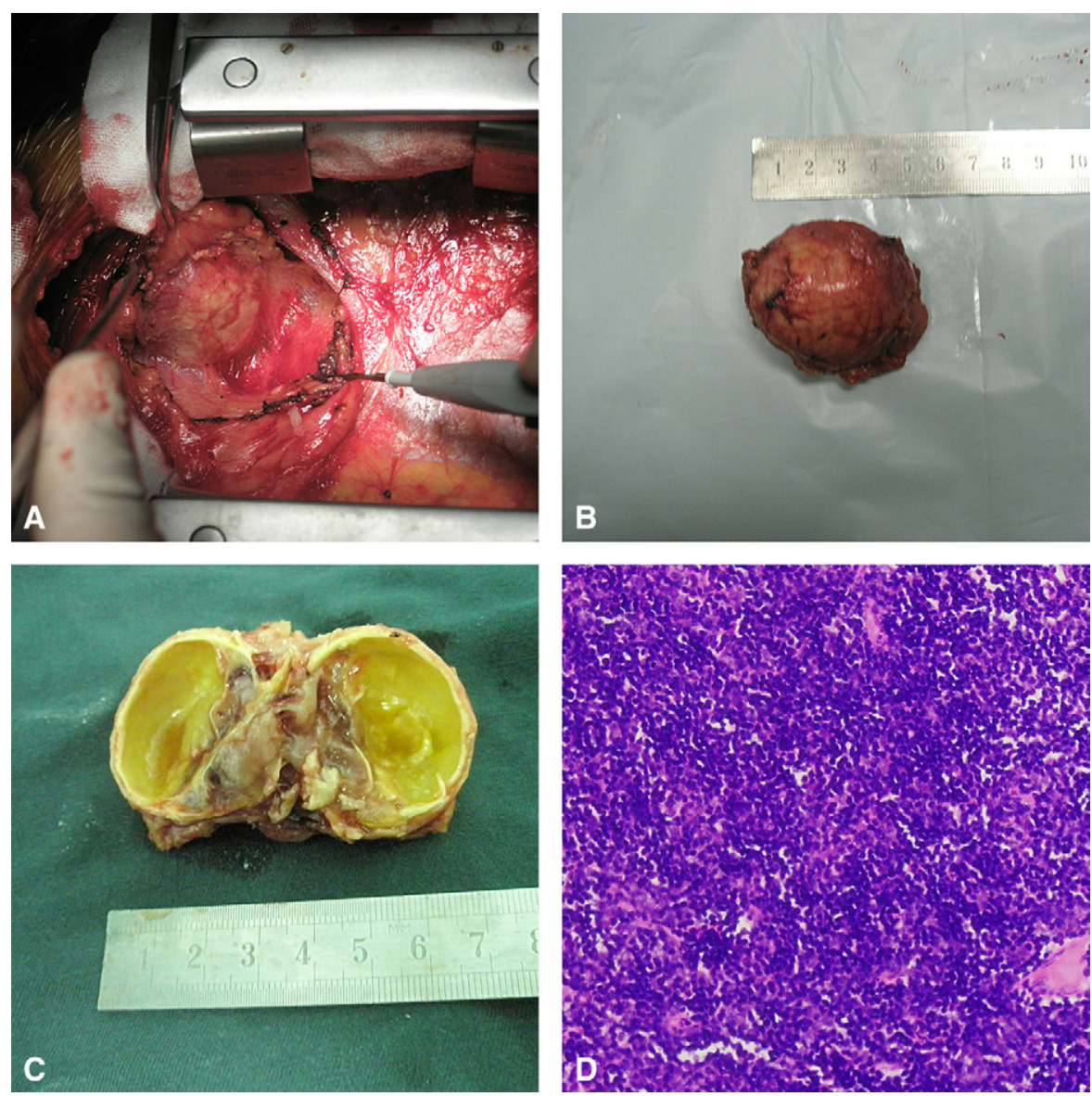

FIGURE 2. A, Intraoperative photograph. B, The excised tumor just like an egg was $5 \times 4 \mathrm{~cm}$ in diameter. $C$, On cut section, the mass appeared as a calcified outer shell, like an eggshell, inside of which there was a great deal of yellowish liquid and some solid tissue with a macroscopic appearance like fish meat. D, Neoplastic tumor cells with polygonal nuclei are intermixed with lymphocytes (hematoxylin-eosin stain; original magnification $\times 400$ ). Histologic analysis was consistent with type B1 thymoma. 